The original publication is available at www.springerlink.com

https://link.springer.com/article/10.1007/s00134-019-05533-0

\title{
Organ donation after circulatory death: current status and future potential
}

Smith $\mathrm{M}^{1}$, Dominguez-Gil B ${ }^{2}$, Greer $\mathrm{DM}^{3}$, Manara $\mathrm{AR}^{4}$, Souter $\mathrm{MJ}^{5}$

${ }^{1}$ Neurocritical Care Unit, The National Hospital for Neurology and Neurosurgery

University College London Hospitals, Queen Square, London, UK

Email: martin.smith@ucl.ac.uk

${ }^{2}$ Organización Nacional de Trasplantes

C/Sinesio Delgado 6, pabellón 3, Madrid, Spain

Email: bdominguez@mscbs.es

${ }^{3}$ Department of Neurology, Boston University School of Medicine, Boston, USA

Email: dgreer@bu.edu

${ }^{4}$ The Intensive Care Unit, Southmead Hospital, North Bristol NHS Trust, Bristol, UK

EMail: alex.manara@nbt.nhs.uk

${ }^{5}$ Department of Anesthesiology \& Pain Medicine, University of Washington, Seattle, Washington, USA

Email: msouter@uw.edu

\section{Corresponding author:}

Martin Smith

Address as above

Short title: Organ donation after circulatory death

Keywords: Donation after circulatory death, ethics, organ donation

\section{Conflicts of interest}

MS is Editor in Chief of the Journal of Neurosurgical Anesthesiology.

BDG is Director General at the Organización Nacional de Trasplantes, Spain. 
DG is Editor-in-Chief of Seminars in Neurology, and receives research support from Bard Medical, Inc, as PI for the INTREPID Clinical Trial.

ARM is the Regional Clinical Lead in Organ Donation for the South West of England.

MJS is the Medical Director for Lifecenter Northwest Organ Procurement agency, serving the Pacific Northwest of the USA.

The authors have no other conflicts of interest to declare. 


\begin{abstract}
The continuing shortage of deceased donor organs for transplantation, and the limited number of potential donors after brain death, has led to a resurgence of interest in donation after circulatory death (DCD). The

processes of warm and cold ischemia threaten the viability of DCD organs, but these can be minimized by well-organized DCD pathways and new techniques of in-situ organ preservation and $e x$-situ resuscitation and repair post-explantation. Transplantation survival after DCD is comparable to donation after brain death despite higher rates of primary non-function and delayed graft function. Countries with successfully implemented DCD programs have achieved this primarily through the establishment of national ethical, professional and legal frameworks to address both public and professional concerns with all aspects of the DCD pathway. There remains a worldwide shortage in organ availability, and it seems unlikely that expanding standard DCD programs in isolation will be sufficient to address this. It is therefore likely that reliance on extended criteria donors will increase, with the attendant imperative to minimize ischemic injury to candidate organs. Normothermic regional perfusion and $e x$-situ perfusion techniques allow enhanced preservation, assessment, resuscitation and/or repair of damaged organs as a way of improving overall organ quality and preventing the unnecessary discarding of DCD organs. This review will outline exemplar controlled and uncontrolled DCD pathways, highlighting practical and logistical considerations that minimize warm and cold ischemia times while addressing potential ethical concerns. Future perspectives will also be discussed.
\end{abstract}

\title{
Take home message
}

Donation after circulatory death (DCD) is an effective means of expanding the potential donor pool, and has comparable transplantation survival to donation after brain death despite higher rates of primary nonfunction and delayed graft function. Countries with successfully implemented DCD programs have achieved this primarily through the establishment of national ethical, professional and legal frameworks to address both public and professional concerns with all aspects of the DCD pathway. 


\section{INTRODUCTION}

The continuing shortage of deceased donor organs for transplantation, and the limited number of potential donors after brain death, has led to a resurgence of interest in donation after circulatory death (DCD) as an effective means of expanding the potential donor pool. In 2017, close to 136,000 solid organ transplants were performed worldwide, but, according to WHO estimates, this activity is sufficient only to meet $10 \%$ of transplant need [1]. The revival in DCD was led by the Maastricht group in The Netherlands in 1995 following their classification of DCD donors. The Maastricht classification was revised in 2013 (Table 1) [2] to more accurately represent current DCD practices in countries which have this form of donation (Table 2). There has been a substantial increase in DCD in the most active countries over the last 15 years (Supplementary Digital Content - Figure 1).

There are two broad categories of DCD. Controlled DCD (cDCD) refers to organ donation after death following the planned withdrawal of life-sustaining therapies (WLST) because these are no longer determined to be in the best interests of the patient (primarily Maastricht category III), and can theoretically occur in any intensive care unit (ICU) or emergency department (ED). Uncontrolled DCD ( $\mathrm{uDCD}$ ) on the other hand is organ retrieval following death after an unexpected and irreversible cardiac arrest (primarily Maastricht categories IIa and IIb), and can only occur in centers where facilities for organ retrieval and perfusion are immediately available [3]. While the potential for DCD should be considered in the Emergency Department (ED) and also after failed CPR or whenever WLST is being considered in other hospital locations, given the morbidities and disease states contributing to the decision to WLST, DCD it is most often considered in the ICU.

Kidney, liver, pancreas, lung and, recently, heart donation are eligible for $\mathrm{cDCD}$, although this varies by country [1]. In uDCD, only kidneys, livers and lungs have successfully been transplanted to date. The processes of warm and cold ischemia threaten the viability of DCD organs. However, recent data confirm comparable transplantation survival after DCD and donation after brain death (DBD) despite higher rates 
of delayed graft function overall [4-6] and primary non-function and higher frequency of biliary complications after DCD liver transplantation [7]. Both cDCD and uDCD offer great potential for tissue donation.

This review will outline exemplar cDCD and uDCD pathways, highlighting practical and logistical considerations that minimize warm and cold ischemia times while addressing potential ethical concerns. Future perspectives will also be discussed.

\section{CONTROLLED DONATION AFTER CIRCULATORY DEATH}

In circumstances where a patient or their surrogates have elected to proceed with end-of-life care, consideration should be given to the option of $\mathrm{cDCD}$. A request to authorize donation after death should be made following, but independent, of the decision to WLST.

A number of important operating principles guide the CDCD pathway, and these are described in detail below. An idealized pathway is shown in Figure 1.

\section{Authorization for donation}

A prior decision to WLST is a prerequisite for an approach to a patient or their surrogate(s) to discuss donation after death. Critically ill patients admitted to hospital may be considered potential candidates for deceased organ donation, and the hospital record should initially be reviewed for eligibility. If a patient or their surrogates elect for end-of-life care, subsequent approaches for organ donation should be undertaken by trained requestors as this improves authorization rates [8;9]. If the patient has already authorized donation (e.g. via a donor registry or donor card), the donation coordination staff should engage only after a decision has been made that end-of-life care is appropriate. 
The site and timing of subsequent WLST should facilitate organ procurement as rapidly as possible after death to minimize the warm ischemia time post-asystole. Authorization for cDCD should include explanation to patients and surrogates of any requirement for transfer to an operating room or adjacent area for WLST, and the need for family members to leave shortly after death is declared. The operating room presents considerable logistical advantages for WLST, but challenges privacy for the patient and surrogates/family, and may lack appropriate staffing and range of medications. WLST in the ICU alleviates these concerns, but with potentially unacceptable increases in warm ischemia times during transfer of the deceased to the operating room. The postoperative recovery area may afford a useful compromise. There are no clear data on the most appropriate location for WLST, only evidence of variability [10].

\section{Eligibility for controlled donation after circulatory death}

Eligibility for $\mathrm{cDCD}$ may be affected by the disease processes contributing to end-of-life decisions, including previous medical history and comorbidities. The risk of neoplastic or infectious disease transmission to recipients should be assessed, alongside evaluation of individual organ function. The latter includes the effects of age and chronic disease, and anticipation of further insults to potentially transplantable organs during the agonal phase [11]. Donors up to the age of 85 years may be evaluated, with other (limited) contraindications similar to all types of donation.

Each organ should be assessed individually because of differing susceptibilities to comorbidities and ischemia-reperfusion injury. In each case, the donation team rather than the clinical staff responsible for the patient's care should determine eligibility. An important factor is the likelihood of death occurring within a specific period after WLST as accumulated anoxic and ischemic injury during physiological deterioration may result in irreversible injury to potentially transplantable organs.

\section{Donor screening}


Every organ donor must be screened to determine tissue compatibility and potential risks to recipients. The timing of WLST is scheduled to allow completion of serological screening and tissue matching. This may take up to 24 hours, and time estimates must be communicated to the patient, surrogates and staff. In exceptional circumstances urgent $\mathrm{CDCD}$ procurement may proceed with organs maintained using ex-situ perfusion while screening and matching is completed (see below).

\section{End-of-life care}

The quality and degree of end-of-life care must not be affected by the potential for organ donation. Bedside staff should be competent in the administration and titration of palliative sedation and analgesia, targeted only at symptomatic relief, thus avoiding any misperceptions of intent.

\section{Avoidance of conflicts of interest and donation stand down}

Organ procurement personnel must not be involved in the management of end-of-life care, and should not be in the patient's presence from WLST to declaration of death. They may prepare and drape the patient prior to WLST if appropriate, but should withdraw thereafter [12].

Death might not occur within the eligibility period for the organ(s) in question. Alternative management pathways in this circumstance should be defined locally, and communicated to the patient and surrogates during the authorization process. Potentially transplantable organs are exposed to a significant period of warm ischemia time during the cDCD process (Figure 2). In general terms the total period of warm ischemia extends from the moment of the WLST to organ perfusion, whereas functional ischemia extends from the moment that candidate organ perfusion is compromised (during cardiorespiratory deterioration and collapse) to organ perfusion [13]. Warm ischemia time can be minimized to some extent by maintaining cardiovascular support and delaying WLST until pre-donation checks are completed. One of the most significant factors in organ viability is likelihood of death occurring within a window period for each individual organ (liver \& heart 20-30 minutes, lungs and pancreas 60 minutes, kidneys 90-120 
minutes), with the duration of the functional and warm ischemia times impacting upon transplant outcomes $[6 ; 14 ; 15]$. There are varied definitions of warm ischemia time, making comparisons difficult. While all agree on an endpoint of cold perfusion flush, the start of warm ischemia time has been variably defined as initiation of WLST, mean arterial pressure of $60 \mathrm{~mm} \mathrm{Hg}$ (organ hypoperfusion), systolic arterial pressure $<35-60 \mathrm{mmHg}$, oxygen saturation $<25-70 \%$, or cardiac arrest [16].

Various models have been developed to predict the likelihood of death within the eligible window, but all have limited accuracy that at best equate to a stand down rate of around $20 \%$ [15;17-20]. Alternative models calculate the risk of graft failure based on donor characteristics and WLST variables [21], but these also fail to eliminate stand-downs. Some argue that every potential cDCD donor should be pursued [20].

\section{Antemortem procedures}

Where legal considerations permit, a variety of antemortem interventions, including femoral cannulation for regional organ perfusion, anticoagulation or vasodilatation, can be implemented to minimize ischemic injury and improve transplant outcomes [13]. These require careful and detailed explanations and informed consent, although, given the limited high-quality evidence available of beneficial effects on post-transplant outcomes [22], some elect to postpone such interventions until after death.

\section{Diagnosis of death}

Death should be diagnosed expeditiously, while meeting appropriate legal standards. Declaration of death is made on absence of circulatory activity (e.g. no pulse, blood pressure, heart sounds, neurologic response or breathing) [23], but invasive arterial pressure monitoring can objectively clarify the diagnosis [16]. Electrocardiographic activity may persist for some time after death. Surrogates and other family members should be swiftly conducted from the room after declaration of death. The permanence of death is confirmed by a mandatory but internationally variable 'no-touch' period of observation (usually 5 
minutes) of continuous cardio-respiratory arrest before organ procurement can begin [12]. Some suggest that this time could be used to transfer the patient to the operating room [24]. As well as variations in the duration of the non-touch period between countries, the means that are accepted to assess absence of circulation (e.g. ECG, invasive blood pressure monitoring, echocardiography) also vary.

\section{UNCONTROLLED DONATION AFTER CIRCULATORY DEATH}

In 2006, the Institute of Medicine estimated that uDCD could increase the potential donor pool by 22,000 annually in the US alone, and urged for the development of this type of donation [25]. Despite these calls, no uDCD program has yet been introduced in the US [26]. The EuReCa study identified almost 7,000 cases of witnessed out-of-hospital cardiac arrest treated by emergency medical services (EMS) in 27 European countries during a one month period [27]. Return of spontaneous circulation occurred in only $28.6 \%$ of these patients, revealing a large missed potential for UDCD which has also been identified in other studies [28;29]. Despite this, only a limited number of European countries have introduced uDCD programs (Table 2), and many of these have limited uDCD activity. Quantitatively, the most important programs have been developed in France, the Russian Federation (type IIb) and Spain. The limited activity in Europe is surprising bearing in mind that the 2015 European Resuscitation Guidelines state that “(...) after stopping CPR, the possibility of ongoing support of the circulation and transport to a dedicated centre in perspective of organ donation should be considered" [30].

The most common reasons for countries failing to introduce or consider uDCD programs are absence of an appropriate regulatory framework, legal prohibition of the practice, lack of organizational capacity or technical expertise, and limited confidence in such programs (in particular on transplantation outcomes) [31]. While international consensus would likely assist in the development of national uDCD programs, it will not impact the need to clarify nation-specific ethical or legislative issues. Successful uDCD programs will therefore continue to rely on a national regulatory framework establishing the legality and ethical 
acceptability of fundamental aspects of the procedure, as well as on societal and professional consensus [32].

The changes to the Maastricht classification in 2013 subdivided category II DCD into IIa and IIb to describe donation after out-of-hospital and in-hospital cardiac arrest, respectively [2]. This change was made because the location of the cardiac arrest is associated with different comorbidities and varying durations of warm ischemia time in potential donors. The uDCD process is similar for all potential donors, but IIa donation presents the greatest logistical challenge.

\section{Initiation of the uDCD pathway}

The category IIa donation pathway (Figure 3) is initiated when an EMS attends a witnessed, unexpected cardiac arrest in a patient in whom resuscitation is unsuccessful despite advanced cardio-pulmonary resuscitation (aCPR). If the person meets a set of selection criteria - age $<55-60$ years, duration of cardiac arrest prior to initiation of aCPR < 15-20 minutes, no apparent relevant comorbidities and absence of exsanguinating lesion [32] - the EMS contacts the donor coordinator at the receiving hospital who evaluates the patient as a potential organ donor. If aCPR protocols determine immediate transfer to hospital for therapeutic reasons, the uDCD procedure is initiated in hospital if aCPR is finally deemed unsuccessful. During transfer of the potential uDCD donor to the hospital (or within hospital), cardiac compression and mechanical ventilation are maintained with the sole purpose of preserving potentially transplantable organs as aCPR has already been determined to be futile. Physicians at the hospital, independent of EMS and the donor/transplant team, declare the death of the individual after confirming that no further therapeutic efforts are indicated and after observing a period of absence of spontaneous breathing and circulation. This no-touch period varies between 5 (in most countries) and 20 minutes (in Italy) [31].

\section{Post-mortem organ preservation}


Following determination of death, cardiac compression and mechanical ventilation may be re-established (in some countries) to ensure organ preservation. This is justified on the basis that death has already been declared following exhausted aCPR measures, and brain death assumed because of prolonged periods of low or no-flow [33].

In-situ organ preservation measures are relevant to both $\mathrm{cDCD}$ and $\mathrm{UDCD}$, although of more relevance in the latter because of the greater likelihood of warm ischemia-related organ injury. Such techniques consist either of in-situ cooling of kidneys using a double-balloon-triple lumen catheter technique, or the establishment of hypothermic or normothermic regional perfusion (nRP) of abdominal organs with an ECMO device. In-situ preservation strategies provide time to complete consent and authorization requirements, evaluate the individual's suitability for donation, and, in the case of liver donation, the opportunity to assess organ viability by monitoring transaminase levels and other parameters that reflect the quality of organ preservation [32;34]. For lung preservation, pleural drainage tubes are inserted and cold preservation fluid (or saline serum) is instilled until the pleural cavities are completely filled and the lungs fully collapsed [34]. In some countries, machine perfusion is considered mandatory for ex-situ preservation (see below), despite the absence of definite evidence that it has any impact on organ viability or post-transplant outcomes.

\section{Ascertaining an individual's wishes}

The deceased person's wishes regarding organ donation are ascertained via several methods, including donor registries, advanced directives, and after discussion with surrogates [32]. The timing of the surrogate discussion varies. In Spain it may take place at any time between the moment when aCPR is deemed unsuccessful to the moment when in situ preservation is initiated [34]. Transparency is paramount during interactions with families while, at the same time, balancing their emotional needs; according to predefined scenarios, information is progressively released [35]. 


\section{Outcomes}

$\mathrm{uDCD}$ has a lower effectiveness than DBD and $\mathrm{CDCD}$, and a high percentage of potential uDCD donors do not transition to actual donation [36]. Moreover, the percentage of actual uDCD donors from whom at least one organ is transplanted is less than $80 \%$, with fewer than 2 organs transplanted per donor [31]. Poor preservation is the main reason to discard abdominal organs once recovered [37]. Importantly, uDCD donors have great potential for tissue donation.

Results of organ transplantation from uDCD donors are considered acceptable, though amenable to improvement. Kidney transplants have adequate short and long-term outcomes, despite a higher incidence of primary non-function and delayed graft function compared with DBD and cDCD organs [32;34;38-40]. In a recent Spanish cohort study of 517 uDCD transplants, standard in-situ cooling of kidneys was associated with a 5.6 increase in the risk of graft loss during the first year post-transplant compared to nRP [37]. Two French studies have also revealed that, compared to in-situ cooling, nRP is associated with significantly improved graft function at two years post-transplantation [38;39]. Increased donor age is an important factor that negatively impacts kidney graft survival [41]. Livers have only been successfully transplanted following nRP, and transplant outcomes can be excellent with careful donor selection [32;34;42]. Preliminary experience with lungs from uDCD donors also shows acceptable post-transplant survival $[32 ; 34 ; 43]$.

\section{ETHICAL CONSIDERATIONS}

The primary duty of care of any doctor is to ensure that their patient's treatment is directed at ensuring survival with the best possible outcome. However, after a decision to WLST or stop CPR has been reached, doctors have a professional and ethical obligation to consider organ donation as a routine part of end-of-life care [44]. While the best interests of an individual must always respect their right to a peaceful and dignified death, it should also ensure that their values and preferences are included in a bespoke endof-life care plan, including the option of organ donation if this is the patient's wish [45]. Many healthcare 
professionals have concerns at the interface between end-of life care and DCD because of perceptions of conflicts of interest, interpretation of a patient's best interests, observation of the dead donor rule, and which (or whether) ante-mortem and post-mortem interventions to improve transplant outcomes are lawful and/or ethical. Such concerns can be mitigated to some extent by education and familiarity with national guidelines [46]. Despite this, new ethical and professional challenges have arisen as boundaries in DCD are challenged.

\section{Minimizing perceptions of conflicts of interest}

cDCD is the only form of deceased organ donation where consideration of donation is made while the patient is still alive. Consequently clinicians must never be perceived as having a conflict of interest. Decisions to proceed with end-of-life care or to abandon aCPR should always be disconnected from any consideration of organ donation. Legislation which places primacy on an individual's best interests are fundamental in minimizing perceptions of conflicts of interest, and, importantly, also broadens the interpretation of best interests to include not only an individual's best medical interests, but also their values, beliefs and preferences, including an expressed wish to donate their organs after their death [44]. National and international professional end-of-life care guidance now places a duty on doctors to consider organ and tissue donation as an integral part of end-of-life care, reinforcing the fundamental importance of respecting a patient's best interests at all times, including after their death [30;47-49].

In countries where it is legal, such as Belgium and in The Netherlands, DCD has been performed after euthanasia [50]. While this respects an individual patient's autonomy to donate after their death, it raises several ethical issues and is only applicable in the few jurisdictions where euthanasia is allowed.

\section{Antemortem interventions}

cDCD cannot be practiced without some alterations in routine end-of-life practices [3]. However, whether interventions applied to a living patient with the sole purpose of increasing the likelihood of donation and 
improved transplant outcomes are appropriate remains a matter of intense debate, and varies

internationally. Antemortem interventions can be simple and minimally invasive, such as blood sampling, or complex and invasive, such as endotracheal intubation [51]. It is essential that countries practicing DCD determine which (if any) interventions are both ethical and legal by considering the potential benefits and harms of each (Supplementary Digital Content - Table 1) [47].

\section{Timing of withdrawal of life-sustaining therapies}

The perils of early WLST in patients with devastating brain injury have been brought into sharp focus by reports of survival of patients in whom end-of-life care was delayed to allow $\mathrm{cDCD}$, and after donation had been authorized [52]. This in effect meant that those patients whose surrogates declined organ donation were denied any chance, albeit small, of survival. Subsequently, national guidelines on the early management of devastating brain injury have recommended delaying WLST for up to 72 hours to allow a period of stabilization and observation [53;54]. Such approaches align with the established and successful pathways for the management of post-cardiac arrest patients [55]. Delaying the decisions to WLST reduces perceptions of conflicts of interest, and offer on-going support and improved prognostication to all patients with devastating brain injury, not only to those whose families have agreed to donation. It also provides longer periods for decoupling conversations about futility and organ donation, and can, in certain circumstances, allow patients with devastating brain injury to progress to brain death and potentially shift from DCD to DBD [56].

\section{Extracorporeal oxygenation techniques}

Recent attention has also focused on decisions to use extracorporeal oxygenation techniques while attempting to achieve restoration of spontaneous circulation. While extracorporeal assisted CPR (eCPR), which provides oxygenated blood to the whole body, is a promising technique, its indications, riskbenefits and cost-effectiveness remain undefined [57]. Moreover, it could be perceived that the widened indications and practice of eCPR have potential to conflict with uDCD [58]. In practice, uDCD should 
only be considered when aCPR has been exhausted according to local protocols. Therefore, if these protocols include eCPR, the uDCD pathway should only be activated when this has been terminated. The feasibility of the integration of eCPR and $\mathrm{UDCD}$ programs has recently been described in refractory cardiac arrest, leading to successful kidney transplantation [59].

$\mathrm{nRP}$ techniques increase the number of organs available for transplantation and improve transplantation outcomes after cDCD, but ante-mortem cannulation of vessels and concern about re-establishment of the circulation after the determination of death bring ethical concerns (see below).

\section{Timing of confirmation of death}

The point at which death can be confirmed after loss of the circulation varies internationally [23], and continues to be debated in an attempt to achieve consensus [60]. The greater acceptance that all human death is based on permanent loss of brain function, usually defined as the capacity for consciousness and all brainstem function, allows the confident confirmation of death soon after loss of the circulation. A recent literature review concluded that consciousness is lost within 21 seconds after cessation of the circulation, the EEG becomes isoelectric within 30 seconds, and visual evoked potentials are lost within 35 seconds [61]. Brain activity and function cannot resume without return of the circulation, and, in the context of DCD, this can only occur if there is spontaneous restoration (auto-resuscitation) because a decision has already been made to terminate or withhold aCPR. Most countries practicing DCD accept that 5 minutes of continuous loss of the circulation and apnea is sufficient to exclude the possibility of auto-resuscitation, and that death can be confidently confirmed at this point [23]. However, diagnosing death at this point is conditional on a prohibition of any post-mortem interventions that have potential to restore cerebral perfusion at a time when the brain may still, theoretically at least, be responsive to reperfusion.

\section{FUTURE PERSPECTIVES}


The substantial unrealized potential for DCD could not only increase the availability of organs for transplantation, but also offer more patients the opportunity to donate. Countries that have successfully implemented DCD programs have done so primarily by establishing a national ethical, professional and legal framework to address both public and professional concerns with all aspects of the DCD pathway [3]. Robust DCD programs increase the donor pool with minimal impact on the rate of other donation types [62]. However, even a large expansion of standard DCD programs will not address the worldwide shortfall in organ availability, increasing reliance on organs from extended criteria donors (ECD). This has driven research into ways to improve the quality of organs and prevent unnecessary discarding of DCD organs.

\section{Normothermic regional perfusion}

Experience with nRP in uDCD has generated interest in its potential applications in cDCD. In addition to its reconditioning potential, nRP can turn an urgent into an elective organ recovery procedure and reduce organ damage due to surgical events [63]. It also allows assessment of organ function prior to transplantation, assisting in the optimal selection of grafts to maximize posttransplant outcomes, particularly in cDCD liver and heart transplantation [64]. Although the experience of using nRP in $\mathrm{CDCD}$ is still limited, published series support these theoretical benefits and report promising results in terms of numbers of organs recovered and transplantation outcomes [65-67]. nRP also seems to allow a safe expansion of donor age, a factor which has classically been a major determinant of recipient outcomes [68]. Despite its potential benefits, there are ethical issues surrounding the use of nRP in DCD. The ante-mortem cannulation of vessels to facilitate nRP and decrease the duration of warm ischemia, or the reestablishment of circulation after the determination of death, are the most challenging [69]. Specific authorization for these interventions, and strategies to avoid reperfusion of the brain, such as clamping the aorta or the aortic arch vessels to exclude the cerebral circulation, have been proposed as ways to respect the interests of 
all those concerned [70]. However, these ethical challenges will not be fully resolved until there is definitive evidence that nRP substantially contributes to improved transplantation outcomes.

\section{Ex-situ perfusion}

Newer techniques such as hypo- and normothermic machine ex-situ perfusion also improve preservation, assessment, resuscitation and/or repair of damaged organs. Preclinical studies have confirmed that normothermic perfusion effectively restores metabolism, replenishes cellular ATP, and upregulates repair mechanisms in kidneys [71]. In a small clinical series of 18 ECD kidneys, ex-situ normothermic perfusion resulted in a substantially lower need for dialysis in the first week post-transplant, with similar one-year graft and patient survival compared to kidneys subject to static cold storage only [72]. A Phase II randomized controlled trial assessing the efficacy of ex-situ perfusion compared with static cold storage in kidney donation is currently underway in the UK [73].

The liver is particularly sensitive to ischemic injury, and limited potential for assessment of liver graft function prior to transplantation is mainly linked to current storage techniques. Moreover, livers from ECDs tolerate static cold storage poorly resulting in a higher risk of primary and delayed graft dysfunction, and biliary complications, compared with standard criteria organs [74]. Ex-situ liver perfusion allows extended periods for graft assessment and modification. In a recent study, 5 of 7 primarily declined high-risk grafts were successfully transplanted after assessment using normothermic ex-situ liver perfusion [75]. The preservation time for liver grafts is increased to more than $24 \mathrm{~h}$ with $e x$ situ perfusion techniques, offering time for comprehensive assessment and treatment of EDC organs, and greater flexibility in scheduling recipient surgery [74].

$E x$-situ lung perfusion allows an objective assessment of lung function, thereby overcoming the uncertainties associated with in-vivo evaluation which leads to high rates of unnecessary decisions to abort lung retrieval [76]. Ex-situ lung perfusion also allows lungs to be maintained for many hours 
without deterioration in function thereby allowing longer periods to obtain histopathological or microbiological results [77], as well as the potential to treat injured donor lungs prior to transplantation [76]. Heart transplantation from DCD donors is also emerging as a realistic opportunity as longer preservation times become a reality. As for other organs, ex-vivo heart perfusion allows for the possibility for evaluation and reconditioning of the isolated heart before transplantation [78].

While $e x$-situ perfusion techniques are expensive, the relatively small incremental cost must be balanced against the potential benefits (clinical and cost) from improved post-transplant organ function. Organ repair and restoration techniques have great potential to improve DCD recipient outcomes by allowing organs currently considered unsuitable for transplantation to be safely implanted after repair and reconditioning. It seems certain that the role of ex-vivo organ repair in DCD must be further developed if the global organ shortage is to be reconciled with demand.

\section{ReferencesReference List}

1. Manyalich $\mathrm{M}$, Nelson $\mathrm{H}$, Delmonico FL: The need and opportunity for donation after circulatory death worldwide. Curr.Opin.Organ Transplant. 2018, 23:136-141.

2. Thuong M, Ruiz A, Evrard P, Kuiper M, Boffa C, Akhtar MZ, Neuberger J, Ploeg R: New classification of donation after circulatory death donors definitions and terminology. Transpl.Int. 2016, 29:749-759.

3. Manara AR, Murphy PG, O'Callaghan G: Donation after circulatory death. Br.J Anaesth. 2012, 108 Suppl 1:i108-i121.

4. Foss S, Nordheim E, Sorensen DW, Syversen TB, Midtvedt K, Asberg A, Dahl T, Bakkan PA, Foss AE, Geiran OR, Fiane AE, Line PD: First Scandinavian Protocol for Controlled Donation After Circulatory Death Using Normothermic Regional Perfusion. Transplant.Direct. 2018, 4:e366.

5. Inci I: Donors after cardiocirculatory death and lung transplantation. $J$ Thorac.Dis. 2017, 9:2660-2669. 
6. Summers DM, Watson CJ, Pettigrew GJ, Johnson RJ, Collett D, Neuberger JM, Bradley JA: Kidney donation after circulatory death (DCD): state of the art. Kidney Int. 2015, 88:241-249.

7. Tang JX, Na N, Li JJ, Fan L, Weng RH, Jiang N: Outcomes of Controlled Donation After Cardiac Death Compared With Donation After Brain Death in Liver Transplantation: A Systematic Review and Meta-analysis. Transplant.Proc. 2018, 50:33-41.

8. Hulme W, Allen J, Manara AR, Murphy PG, Gardiner D, Poppitt E: Factors influencing the family consent rate for organ donation in the UK. Anaesthesia 2016, 71:1053-1063.

9. Siminoff LA, Gordon N, Hewlett J, Arnold RM: Factors influencing families' consent for donation of solid organs for transplantation. JAMA 2001, 286:71-77.

10. Mitro G, Warnock R, Wiederhold P, Jiles K, Ortiz J: Consistency of DCD procurement procedures across organ procurement organizations - preliminary findings [abstract]. American Transplant Congress Archives - ATC Abstracts 2018.

11. Moers C, Leuvenink HG, Ploeg RJ: Donation after cardiac death: evaluation of revisiting an important donor source. Nephrol.Dial.Transplant. 2010, 25:666-673.

12. Reich DJ, Mulligan DC, Abt PL, Pruett TL, Abecassis MM, D'Alessandro A, Pomfret EA, Freeman RB, Markmann JF, Hanto DW, Matas AJ, Roberts JP, Merion RM, Klintmalm GB: ASTS recommended practice guidelines for controlled donation after cardiac death organ procurement and transplantation. Am.J Transplant. 2009, 9:2004-2011.

13. Citerio G, Cypel M, Dobb GJ, Dominguez-Gil B, Frontera JA, Greer DM, Manara AR, Shemie SD, Smith M, Valenza F, Wijdicks EF: Organ donation in adults: a critical care perspective. Intensive Care Med. 2016, 42:305-315.

14. Algahim MF, Love RB: Donation after circulatory death: the current state and technical approaches to organ procurement. Curr.Opin.Organ Transplant. 2015, 20:127-132.

15. Kotsopoulos AMM, Boing-Messing F, Jansen NE, Vos P, Abdo WF: External validation of prediction models for time to death in potential donors after circulatory death. Am.J Transplant. 2018, 18:890-896.

16. Neyrinck A, Van RD, Monbaliu D: Donation after circulatory death: current status. Curr.Opin.Anaesthesiol. 2013, 26:382-390.

17. de Groot YJ, Lingsma HF, Bakker J, Gommers DA, Steyerberg E, Kompanje EJ: External validation of a prognostic model predicting time of death after withdrawal of life support in neurocritical patients. Crit Care Med. 2012, 40:233-238.

18. Rabinstein AA, Yee AH, Mandrekar J, Fugate JE, de Groot YJ, Kompanje EJ, Shutter LA, Freeman WD, Rubin MA, Wijdicks EF: Prediction of potential for organ donation after 
cardiac death in patients in neurocritical state: a prospective observational study. Lancet Neurol. 2012, 11:414-419.

19. Rusinova K, Cerny V, Kukal J, Pokorna E: Expanding the DCD donor pool: prediction of time to death after removal of life-sustaining treatments. Intensive Care Med. 2015, 41:1719-1720.

20. Wind J, Snoeijs MG, Brugman CA, Vervelde J, Zwaveling J, van Mook WN, van Heurn EL: Prediction of time of death after withdrawal of life-sustaining treatment in potential donors after cardiac death*. Crit Care Med. 2012, 40:766-769.

21. Schlegel A, Kalisvaart M, Scalera I, Laing RW, Mergental H, Mirza DF, Perera T, Isaac J, Dutkowski P, Muiesan P: The UK DCD Risk Score: A new proposal to define futility in donation-after-circulatory-death liver transplantation. J Hepatol. 2018, 68:456-464.

22. Dikdan GS, Mora-Esteves C, Koneru B: Review of randomized clinical trials of donor management and organ preservation in deceased donors: opportunities and issues. Transplantation 2012, 94:425-441.

23. Dhanani S, Hornby L, Ward R, Shemie S: Variability in the determination of death after cardiac arrest: a review of guidelines and statements. J Intensive Care Med. 2012, 27:238-252.

24. Morrissey PE, Monaco AP: Donation after circulatory death: current practices, ongoing challenges, and potential improvements. Transplantation 2014, 97:258-264.

25. Childress JF, Liverman $\mathrm{CT}$, Committee on increasing organ donation rates: Organ Donation: Opportunities for Action. Washington, D.C.: National Academies Press; 2006.

26. Wall SP, Kaufman BJ, Williams N, Norman EM, Gilbert AJ, Munjal KG, Maikhor S, Goldstein MJ, Rivera JE, Lerner H, Meyers C, Machado M, Montella S, Pressman M, Teperman LW, Dubler NN, Goldfrank LR: Lesson From the New York City Out-ofHospital Uncontrolled Donation After Circulatory Determination of Death Program. Ann.Emerg.Med. 2016, 67:531-537.

27. Grasner JT, Lefering R, Koster RW, Masterson S, Bottiger BW, Herlitz J, Wnent J, Tjelmeland IB, Ortiz FR, Maurer H, Baubin M, Mols P, Hadzibegovic I, loannides M, Skulec R, Wissenberg M, Salo A, Hubert H, Nikolaou NI, Loczi G, Svavarsdottir H, Semeraro F, Wright PJ, Clarens C, Pijls R, Cebula G, Correia VG, Cimpoesu D, Raffay V, Trenkler S, Markota A, Stromsoe A, Burkart R, Perkins GD, Bossaert LL: EuReCa ONE-27 Nations, ONE Europe, ONE Registry: A prospective one month analysis of out-ofhospital cardiac arrest outcomes in 27 countries in Europe. Resuscitation 2016, 105:188-195.

28. Jabre $P$, Bougouin W, Dumas F, Carli P, Antoine C, Jacob L, Dahan B, Beganton F, Empana JP, Marijon E, Karam N, Loupy A, Lefaucheur C, Jost D, Cariou A, Adnet F, Rea TD, Jouven 
X: Early Identification of Patients With Out-of-Hospital Cardiac Arrest With No Chance of Survival and Consideration for Organ Donation. Ann.Intern.Med. 2016, 165:770-778.

29. Navalpotro-Pascual JM, Echarri-Sucunza A, Mateos-Rodriguez A, Peinado-Vallejo F, Del Valle PF, Alonso-Moreno D, Del Pozo-Perez C, Mier-Ruiz MV, Ruiz-Azpiazu JI, BravoCastello J, Martinez-Cuellar N, Saez-Jimenez A, Lopez-Unanua C, Anton-Ramas R, Escriche-Lopez MDC, Giraldo-Sebastia JM, Garcia-Ochoa MJ, Martin-Sanchez E, BorrazClares D, Del Valle MM, Carriedo-Scher C, Rosell-Ortiz F: Uncontrolled donation programs after out-of-hospital cardiac arrest. An estimation of potential donors. Resuscitation 2018, 122:87-91.

30. Bossaert LL, Perkins GD, Askitopoulou H, Raffay VI, Greif R, Haywood KL, Mentzelopoulos SD, Nolan JP, Van d, V, Xanthos TT: European Resuscitation Council Guidelines for Resuscitation 2015: Section 11. The ethics of resuscitation and end-oflife decisions. Resuscitation 2015, 95:302-311.

31. Dominguez-Gil B, Haase-Kromwijk B, Van LH, Neuberger J, Coene L, Morel P, Corinne A, Muehlbacher F, Brezovsky P, Costa AN, Rozental R, Matesanz R: Current situation of donation after circulatory death in European countries. Transpl.Int. 2011, 24:676-686.

32. Dominguez-Gil B, Duranteau J, Mateos A, Nunez JR, Cheisson G, Corral E, De JW, Del RF, Valero R, Coll E, Thuong M, Akhtar MZ, Matesanz R: Uncontrolled donation after circulatory death: European practices and recommendations for the development and optimization of an effective programme. Transpl.Int. 2016, 29:842-859.

33. Zamperetti N, Bellomo R, Latronico N: Heart donation and transplantation after circulatory death: ethical issues after Europe's first case. Intensive Care Med. 2016, 42:93-95.

34. Minambres E, Rubio JJ, Coll E, Dominguez-Gil B: Donation after circulatory death and its expansion in Spain. Curr.Opin.Organ Transplant. 2018, 23:120-129.

35. Donación en Asistolia en España: Situación actual y Recomendaciones. Documento de Consenso 2012. Donación en Asistolia en España . 2012.

Ref Type: Online Source

36. Fondevila C, Hessheimer AJ, Flores E, Ruiz A, Mestres N, Calatayud D, Paredes D, Rodriguez C, Fuster J, Navasa M, Rimola A, Taura P, Garcia-Valdecasas JC: Applicability and results of Maastricht type 2 donation after cardiac death liver transplantation. Am.J Transplant. 2012, 12:162-170.

37. Del Río F, Andrés A, Padilla M, et al.: Kidney transplantation from uncontrolled donors after circulatory death: the Spanish experience. Kidney Int 2018, In Press.

38. Delsuc C, Faure A, Berthiller J, Dorez D, Matillon X, Meas-Yedid V, Floccard B, Marcotte G, Labeye V, Rabeyrin M, Codas R, Chauvet C, Robinson P, Morelon E, Badet L, Hanf W, 
Rimmele T: Uncontrolled donation after circulatory death: comparison of two kidney preservation protocols on graft outcomes. BMC.Nephrol. 2018, 19:3.

39. Demiselle J, Augusto JF, Videcoq M, Legeard E, Dube L, Templier F, Renaudin K, Sayegh J, Karam G, Blancho G, Dantal J: Transplantation of kidneys from uncontrolled donation after circulatory determination of death: comparison with brain death donors with or without extended criteria and impact of normothermic regional perfusion. Transpl.Int. 2016, 29:432-442.

40. Molina M, Guerrero-Ramos F, Fernandez-Ruiz M, Gonzalez E, Cabrera J, Morales E, Gutierrez E, Hernandez E, Polanco N, Hernandez A, Praga M, Rodriguez-Antolin A, Pamplona M, de la Rosa F, Cavero T, Chico M, Villar A, Justo I, Andres A: Kidney transplant from uncontrolled donation after circulatory death donors maintained by $\mathrm{nECMO}$ has long-term outcomes comparable to standard criteria donation after brain death. Am.J Transplant. 2018.

41. Pieter Hoogland ER, van Smaalen TC, Christiaans MH, van Heurn LW: Kidneys from uncontrolled donors after cardiac death: which kidneys do worse? Transpl.Int. 2013, 26:477-484.

42. De CR, Di SS, Lauterio A, Ferla F, Dell'Acqua A, Zanierato M, De CL: Successful donation after cardiac death liver transplants with prolonged warm ischemia time using normothermic regional perfusion. Liver Transpl. 2017, 23:166-173.

43. Gomez-de-Antonio D, Campo-Canaveral JL, Crowley S, Valdivia D, Cordoba M, Moradiellos J, Naranjo JM, Ussetti $P$, Varela A: Clinical lung transplantation from uncontrolled non-heart-beating donors revisited. J Heart Lung Transplant. 2012, 31:349-353.

44. Dominguez-Gil B, Murphy $P$, Procaccio F: Ten changes that could improve organ donation in the intensive care unit. Intensive Care Med. 2016, 42:264-267.

45. Manara A: Bespoke end-of-life decision making in ICU: has the tailor got the right measurements? Crit Care Med. 2015, 43:909-910.

46. Lee YY, Ranse K, Silvester W, Mehta A, Van HF: Attitudes and self-reported end-of-life care of Australian and New Zealand intensive care doctors in the context of organ donation after circulatory death. Anaesth.Intensive Care 2018, 46:488-497.

47. Academy of Medical Royal Colleges UK Donation Ethics Committee 2011. An ethical framework for controlled donation after circulatory death. 2011.

Ref Type: Online Source

48. Kotloff RM, Blosser S, Fulda GJ, Malinoski D, Ahya VN, Angel L, Byrnes MC, DeVita MA, Grissom TE, Halpern SD, Nakagawa TA, Stock PG, Sudan DL, Wood KE, Anillo SJ, Bleck TP, Eidbo EE, Fowler RA, Glazier AK, Gries C, Hasz R, Herr D, Khan A, Landsberg D, Lebovitz 
DJ, Levine DJ, Mathur M, Naik P, Niemann CU, Nunley DR, O'Connor KJ, Pelletier SJ, Rahman O, Ranjan D, Salim A, Sawyer RG, Shafer T, Sonneti D, Spiro P, Valapour M, Vikraman-Sushama D, Whelan TP: Management of the Potential Organ Donor in the ICU: Society of Critical Care Medicine/American College of Chest Physicians/Association of Organ Procurement Organizations Consensus Statement. Crit Care Med. 2015, 43:1291-1325.

49. Zavalkoff S, Shemie SD, Grimshaw JM, Chasse M, Squires JE, Linklater S, Appleby A, Hartell D, Lalani J, Lotherington K, Knoll G: Potential organ donor identification and system accountability: expert guidance from a Canadian consensus conference. Can.J Anaesth. 2018.

50. van DG, van Bruchem-Visser $R$, de $B$, I: Organ donation after euthanasia, morally acceptable under strict procedural safeguards. Clin.Transplant 2018, 32:e13294.

51. Dominguez-Gil B, Coll E, Elizalde J, Herrero JE, Pont T, Quindos B, Marcelo B, Bodi MA, Martinez A, Nebra A, Guerrero F, Mancino JM, Galan J, Lebron M, Minambres E, Matesanz R: Expanding the Donor Pool Through Intensive Care to Facilitate Organ Donation: Results of a Spanish Multicenter Study. Transplantation 2017, 101:e265e272.

52. Manara AR, Thomas I, Harding R: A case for stopping the early withdrawal of life sustaining therapies in patients with devastating brain injuries. J Intensive Care Soc. 2016, 17:295-301.

53. Harvey D, Butler J, Groves J, Manara A, Menon D, Thomas E, Wilson M: Management of perceived devastating brain injury after hospital admission: a consensus statement from stakeholder professional organizations. Br.J Anaesth. 2018, 120:138-145.

54. Souter MJ, Blissitt PA, Blosser S, Bonomo J, Greer D, Jichici D, Mahanes D, Marcolini EG, Miller C, Sangha K, Yeager S: Recommendations for the Critical Care Management of Devastating Brain Injury: Prognostication, Psychosocial, and Ethical Management : A Position Statement for Healthcare Professionals from the Neurocritical Care Society. Neurocrit.Care 2015, 23:4-13.

55. Manara AR, Menon DK: Withdrawal of treatment after devastating brain injury: postcardiac arrest pathways lead in best practice. Anaesthesia 2017, 72:1179-1184.

56. Broderick AR, Manara A, Bramhall S, Cartmill M, Gardiner D, Neuberger J: A Donation After Circulatory Death Program Has the Potential to Increase the Number of Donors After Brain Death. Crit Care Med. 2016, 44:352-359.

57. Manara AR, Dominguez-Gil B, Perez-Villares JM, Soar J: What follows refractory cardiac arrest: Death, extra-corporeal cardiopulmonary resuscitation (E-CPR), or uncontrolled donation after circulatory death? Resuscitation 2016, 108:A3-A5. 
58. Prabhu A, Parker LS, DeVita MA: Caring for Patients or Organs: New Therapies Raise New Dilemmas in the Emergency Department. Am.J Bioeth. 2017, 17:6-16.

59. Roncon-Albuquerque R, Jr., Gaiao S, Figueiredo $P$, Principe N, Basilio C, Mergulhao $P$, Silva S, Honrado T, Cruz F, Pestana M, Oliveira G, Meira L, Franca A, Almeida-Sousa JP, Araujo F, Paiva JA: An integrated program of extracorporeal membrane oxygenation (ECMO) assisted cardiopulmonary resuscitation and uncontrolled donation after circulatory determination of death in refractory cardiac arrest. Resuscitation 2018, 133:88-94.

60. Shemie SD, Hornby L, Baker A, Teitelbaum J, Torrance S, Young K, Capron AM, Bernat JL, Noel $\mathrm{L}$ : International guideline development for the determination of death. Intensive Care Med. 2014, 40:788-797.

61. Pana R, Hornby L, Shemie SD, Dhanani S, Teitelbaum J: Time to loss of brain function and activity during circulatory arrest. J Crit Care 2016, 34:77-83.

62. Nelson HM, Glazier AK, Delmonico FL: Changing Patterns of Organ Donation: Brain Dead Donors Are Not Being Lost by Donation After Circulatory Death. Transplantation 2016, 100:446-450.

63. Ausania $F$, White SA, Pocock $P$, Manas DM: Kidney damage during organ recovery in donation after circulatory death donors: data from UK National Transplant Database. Am.J Transplant 2012, 12:932-936.

64. Tsui SSL, Oniscu GC: Extending normothermic regional perfusion to the thorax in donors after circulatory death. Curr.Opin.Organ Transplant 2017, 22:245-250.

65. Minambres E, Suberviola B, Dominguez-Gil B, Rodrigo E, Ruiz-San Millan JC, RodriguezSan Juan JC, Ballesteros MA: Improving the Outcomes of Organs Obtained From Controlled Donation After Circulatory Death Donors Using Abdominal Normothermic Regional Perfusion. Am.J Transplant 2017, 17:2165-2172.

66. Rojas-Pena A, Sall LE, Gravel MT, Cooley EG, Pelletier SJ, Bartlett RH, Punch JD: Donation after circulatory determination of death: the university of michigan experience with extracorporeal support. Transplantation 2014, 98:328-334.

67. Ruiz P, Gastaca M, Bustamante FJ, Ventoso A, Palomares I, Prieto M, Fernandez JR, Salvador P, Pijuan JI, Valdivieso A: Favorable Outcomes After Liver Transplantation With Normothermic Regional Perfusion From Donors After Circulatory Death: A SingleCenter Experience. Transplantation 2018.

68. Summers DM, Johnson RJ, Hudson A, Collett D, Watson CJ, Bradley JA: Effect of donor age and cold storage time on outcome in recipients of kidneys donated after circulatory death in the UK: a cohort study. Lancet 2013, 381:727-734. 
69. Dalle Ave AL, Shaw DM, Bernat JL: Ethical Issues in the Use of Extracorporeal Membrane Oxygenation in Controlled Donation After Circulatory Determination of Death. Am.J Transplant 2016, 16:2293-2299.

70. Perez-Villares JM, Rubio JJ, Del RF, Minambres E: Validation of a new proposal to avoid donor resuscitation in controlled donation after circulatory death with normothermic regional perfusion. Resuscitation 2017, 117:46-49.

71. Hosgood SA, Nicholson ML: The evolution of donation after circulatory death donor kidney repair in the United Kingdom. Curr.Opin.Organ Transplant. 2018, 23:130-135.

72. Nicholson ML, Hosgood SA: Renal transplantation after ex vivo normothermic perfusion: the first clinical study. Am.J Transplant. 2013, 13:1246-1252.

73. Hosgood SA, Saeb-Parsy K, Wilson C, Callaghan C, Collett D, Nicholson ML: Protocol of a randomised controlled, open-label trial of ex vivo normothermic perfusion versus static cold storage in donation after circulatory death renal transplantation. BMJ Open. 2017, 7:e012237.

74. Kollmann D, Selzner M: Recent advances in the field of warm ex-vivo liver perfusion. Curr.Opin.Organ Transplant. 2017, 22:555-562.

75. Mergental H, Perera MT, Laing RW, Muiesan P, Isaac JR, Smith A, Stephenson BT, Cilliers $H$, Neil DA, Hubscher SG, Afford SC, Mirza DF: Transplantation of Declined Liver Allografts Following Normothermic Ex-Situ Evaluation. Am.J Transplant. 2016, 16:32353245.

76. Cypel M, Yeung JC, Liu M, Anraku M, Chen F, Karolak W, Sato M, Laratta J, Azad S, Madonik M, Chow CW, Chaparro C, Hutcheon M, Singer LG, Slutsky AS, Yasufuku K, de PM, Pierre AF, Waddell TK, Keshavjee S: Normothermic ex vivo lung perfusion in clinical lung transplantation. N.Engl.J Med. 2011, 364:1431-1440.

77. Greer DM, Valenza F, Citerio G: Improving donor management and transplantation success: more research is needed. Intensive Care Med. 2015, 41:537-540.

78. Dhital KK, Chew HC, Macdonald PS: Donation after circulatory death heart transplantation. Curr.Opin.Organ Transplant. 2017, 22:189-197. 


\section{Legends to figures}

\section{Figure 1}

The pathway for controlled donation after circulatory death

DCD, donation after circulatory death; WLST, withdrawal of life-sustaining therapy

\section{Figure 2}

Warm and cold ischemia in donation after circulatory death

MAP, mean arterial pressure; SBP, systolic blood pressure; $\mathrm{SpO}_{2}$, arterial oxygen saturation; WLST, withdrawal of life-sustaining therapy

\section{Figure 3}

The pathway for uncontrolled donation after circulatory death

$C P R$, cardiopulmonary resuscitation; $h R P$, hypothermic regional perfusion; $n R P$, normothermic regional perfusion 
Table 1

Modified Maastricht criteria for donation after circulatory death (updated 2013)

\begin{tabular}{llll}
\hline Category & Type of DCD & Description & Notes \\
I & N/A & $\begin{array}{l}\text { Found dead } \\
\text { IA: out-of-hospital } \\
\text { IB: in-hospital }\end{array}$ & $\begin{array}{l}\text { Unexpected cardiac arrest with } \\
\text { no attempt at resuscitation. } \\
\text { Can donate tissues (not } \\
\text { suitable as organ donor) }\end{array}$ \\
II & Uncontrolled & $\begin{array}{l}\text { Witnessed cardiac arrest } \\
\text { IIA: out-of-hospital }\end{array}$ & $\begin{array}{l}\text { Unexpected cardiac arrest with } \\
\text { unsuccessful resuscitation }\end{array}$ \\
& IIB: in-hospital & $\begin{array}{l}\text { Withdrawal of life- } \\
\text { sustaining therapy }\end{array}$ & $\begin{array}{l}\text { Primary mode of DCD (only } \\
\text { mode in some countries) }\end{array}$ \\
III & Controlled & $\begin{array}{l}\text { Cardiac arrest after brain } \\
\text { death determination }\end{array}$ & $\begin{array}{l}\text { Unexpected cardiac arrest in a } \\
\text { brain dead patient scheduled } \\
\text { for donation }\end{array}$ \\
& Uncontrolled/Controlled & & \\
\hline
\end{tabular}


Table 2

Modes of donation after circulatory death in different countries

\begin{tabular}{lll|lll}
\hline & Controlled & & \multicolumn{3}{c}{ Uncontrolled } \\
\hline Australia & France & Norway & Austria & Italy & Portugal \\
Austria & Ireland & Spain & Belgium & Latvia & Russia \\
Belgium & Italy & Switzerland & Czech & Lithuania & Spain \\
Canada & Netherlands & Sweden & France & Netherlands & Switzerland \\
China & New Zealand & UK & Israel & Poland & UK \\
$\begin{array}{l}\text { Czech } \\
\text { Republic }\end{array}$ & & USA & & & \\
\hline
\end{tabular}




\section{SUPPLEMENTARY DIGITAL CONTENT}

\section{SDC - Figure 1}

Evolution of donation after circulatory death (rates per million population) in the most active countries from 2003 to 2017. Source: Global Observatory on Organ Donation and Transplantation (http://www.transplant-observatory.org/)

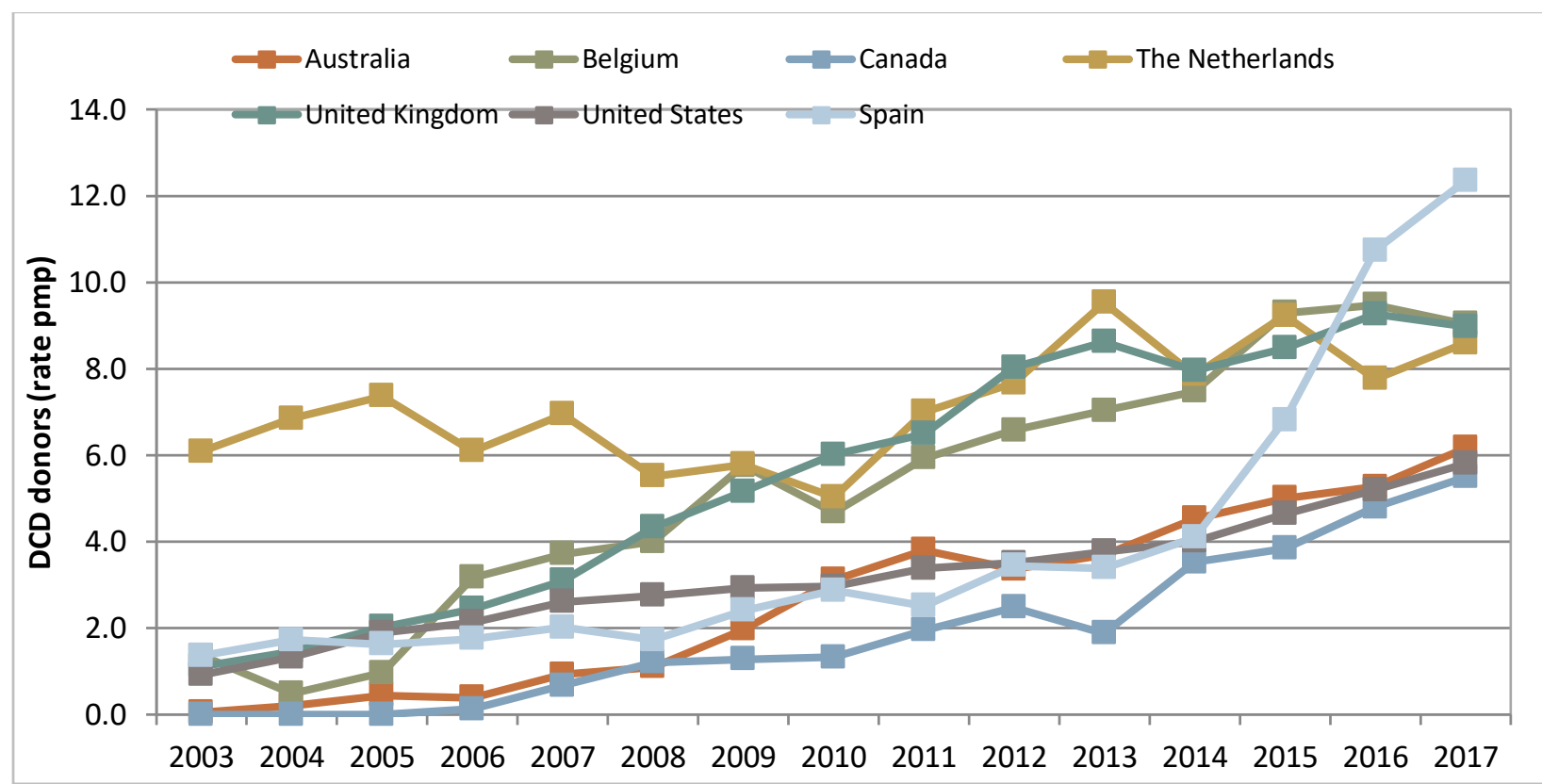


SDC - Table 1

Assessing the balance of whether an individual antemortem intervention is acceptable in an individual patient

\begin{tabular}{|l|l|}
\hline $\begin{array}{l}\text { Factors increasing acceptability of an antemortem } \\
\text { intervention }\end{array}$ & $\begin{array}{l}\text { Factors decreasing acceptability of an } \\
\text { antemortem intervention }\end{array}$ \\
\hline $\begin{array}{l}\text { Strong evidence of patient's wish to donate (e.g. on } \\
\text { organ donor register) }\end{array}$ & $\begin{array}{l}\text { No evidence to support patient's wish to donate (e.g. } \\
\text { wishes unknown to family) }\end{array}$ \\
\hline Intervention minimally invasive & Intervention very invasive \\
\hline Intervention not painful or distressing to patient & $\begin{array}{l}\text { Intervention potentially painful or distressing to } \\
\text { patient }\end{array}$ \\
\hline Intervention not distressing to family or staff & Intervention potentially distressing to family or staff \\
\hline $\begin{array}{l}\text { Strong evidence that intervention will increase the } \\
\text { likelihood of successful donation }\end{array}$ & $\begin{array}{l}\text { Weak or little evidence that intervention will increase } \\
\text { the likelihood of successful donation }\end{array}$ \\
\hline $\begin{array}{l}\text { Strong evidence that intervention will increase organ } \\
\text { utilisation }\end{array}$ & $\begin{array}{l}\text { Weak or little evidence that intervention will increase } \\
\text { organ utilisation }\end{array}$ \\
\hline $\begin{array}{l}\text { Strong evidence that intervention will improve the } \\
\text { viability and function of transplanted organs }\end{array}$ & $\begin{array}{l}\text { Weak or little evidence that intervention will improve } \\
\text { the viability and function of transplanted organs }\end{array}$ \\
\hline Acceptable to the multidisciplinary ICU team & Not acceptable to the multidisciplinary ICU team \\
\hline
\end{tabular}

